\title{
A MULTI-SCALE BIM/GIS FRAMEWORK FOR RAILWAYS ASSET MANAGEMENT
}

\author{
M. Garramone ${ }^{1 *}$, E. Tonelli ${ }^{1}$, M. Scaioni ${ }^{1}$ \\ ${ }^{1}$ Politecnico di Milano, Dept. of Architecture, Built Environment and Construction Engineering, via Ponzio 31, 20133 Milano, Italy \\ emails: (manuel.garramone, eliana.tonelli, marco.scaioni)@polimi.it
}

Commission V, WG V/7

KEYWORDS: Asset Management, BIM/GIS Integration, BIM, Decarbonisation, GIS, Railways

\begin{abstract}
:
Climate change and urban transformations raise new challenges for decision-makers. The United Nations Sustainable Development Goals and The European Green Deal aim for a sustainable economy by reducing emissions of greenhouse gases. An essential task for reaching this result is to minimize transport emissions and their negative impacts on the environment and the human health. Rail is the future of sustainable transport system, and it can be part of the solution in achieving the decarbonisation target. In addition, even more people are using the train and the improvement of the service offered is an essential aspect to fulfil a greater demand for rail transport. More than five million people daily take the train in Italy, and this number is growing over time. It is demonstrated that more investment in rail infrastructure means a greater number of users, and this is even more true when considering the regional rail transport network. This ongoing research aims to test the potential of a Building Information Modelling (BIM) and Geographic Information Systems (GIS) integrated system employed to manage this type of existing infrastructure. A methodology was developed and partly tested on a case study. The purpose is the construction of a system that can be used across different phases of the process: linking the data resulting from BIM and GIS makes possible the development of a federated virtual model used as a single source of truth for project development and asset management.
\end{abstract}

\section{INTRODUCTION}

Asset Management (AM) is a discipline that involves the balancing of costs, opportunities and risks against the desired performance of assets to achieve the organisational objectives (ISO, 2014). In the field of transportation infrastructure, AM is a relatively new discipline and, due to the new urban transformation and climate change challenges, it is necessary to manage them during its whole life-cycle. The attention to these issues has led many countries to adopt specific policies. The Sustainable Development Goals (SDGs) issued and approved by the United Nations' Member States in 2015 would like to promote prosperity while protecting the environment (United Nations, 2015). SDGs 9 and 11 are strictly linked to the infrastructure theme, and they underline the importance of innovation and technological progress as well as the necessity to make cities more resilient and sustainable. The European Green Deal (European Commission, 2019) plans to make the European Union's (EU) economy sustainable by reducing greenhouse gases (GHG) emissions at least $55 \%$ by 2030 and being the first climate-neutral continent by 2050. Transport consumes one-third of all EU's final energy (most of it still comes from burning fossil fuels), so one of the main challenges is to reduce transport emission and its negative impacts on the environment and the human health.

Moreover, the number of people using the train is growing and to fulfil a greater demand for rail transport means to improve the service offered in terms of quantity (frequency and punctuality) and quality (safety and comfort). A fundamental step in this direction has been the development of high-speed rail (HSR) services throughout the last decades. Focusing on the situation in Italy, more than five million people daily take the train to study or work (Istat, 2019). This number is continuously growing over time. HSRs, thanks to their extraordinary growth in service supply, increased the number of carried passengers by 515\% within 2008-2019. This success demonstrates that more investment in rail infrastructure means a greater number of users. This is even more true when considering the regional rail transport. Although there is a general increase $(+5.1 \%$ from 2010 to 2019), the situation is intensely fragmented based on single regional strategies (basically north regions have a positive growth while south regions have a negative one, see Legambiente, 2021). Local or regular railway transports, mainly used by commuters, need a management strategy. For most of them, indeed, different intervention works are necessary, such as railway track adaptation and electrification (see Fig. 1).
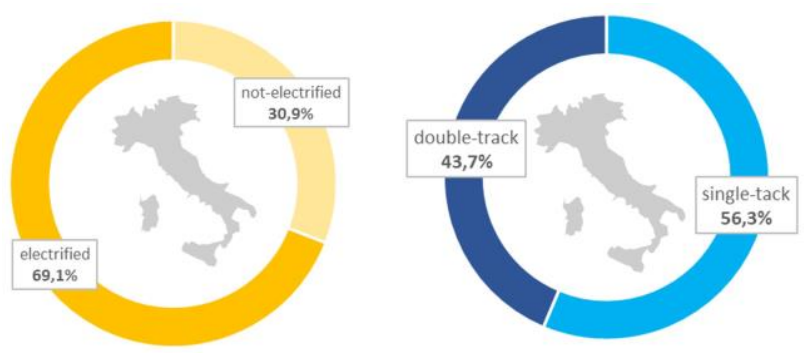

Figure 1. Italian regional railways: electrification and number of tracks (Legambiente, 2021).

Supported by new technologies, the key to handle the problem of renovation and management of regional railways is the digital transformation, which provides a series of opportunities for a positive conversion of the transport sector (Tsakalidis et al., 2020). In particular, the focus is to test the potential of a

\footnotetext{
* Corresponding author.
} 
Building Information Modelling (BIM) and Geographic Information Systems (GIS) integrated system employed to manage this type of existing infrastructure. From the infrastructure AM point of view, the capacity of BIM and GIS for the management, analysis, and visualization of data may provide more insights for increasing the value of assets, detecting and reducing risks and, optimizing decision-making in assets management (Wang et al., 2019). The paper is organised as follow: Section 2 briefly discusses the State of the Art of BIM/GIS integration for Infrastructure Asset Management; Section 3 discusses the framework of the research project; Section 4 presents the case study of a regional railway; finally, Section 5 concludes the paper.

\section{STATE OF THE ART}

The starting point of the research was to investigate the State of the Art of BIM/GIS integration for Infrastructure Asset Management (AM).

\subsection{Methodology}

The first step was querying Scopus and Web of Science databases with a search code, selected through an iterative process. Then, the categories not related to the scope of the research were excluded from the results. To better identify how the scientific community handled this topic and understand recent trends and gaps in the research, a bibliometric analysis with R Package Bibliometrix (Aria and Cuccurullo, 2017) was conducted on the two databases to compare different results to have a more complete list of articles. More details can be found in Garramone et al. (2020).

\subsection{Results}

The analysis confirms that the topic is gaining momentum and also that AM is supported by GIS or BIM tools, yet a strong link between the two tools cannot be identified. The majority of articles report about a BIM (32\%) or a GIS (52\%) approach, while only a small percentage of them (16\%) consider the integration of both. To underline the use of BIM, GIS and BIM/GIS for Infrastructure AM, the articles have been analysed according to the type of approach and technology adopted in AM.

The main topics found about BIM for infrastructure AM are:

- Information management: a BIM model for AM should is setup since the beginning of the project (Love et al., 2015), considering the whole assets' life-cycle in order to facilitate the information exchange across the several stages of the management process (Abdirad and Dossick, 2020);

- Decision making: the BIM model, properly structured, can support strategic decision-making against uncertainty in asset management (Heaton et al., 2019) and may support operation and maintenance by integrating the existing AM and the model-related data (Dell'Acqua et al., 2018).

\section{GIS for infrastructure AM is usually linked to:}

- Risk assessment: to assess the system vulnerabilities and for disaster prevention, frequency and severity (Nakamura et al., n.d.);

- Asset performance monitoring: to support the management of transportation assets (Torres-Machi et al., 2018) and to simulate deterioration, failure, remaining life-cycle, and network robustness of utility assets (Ward et al., 2017); and

- Asset cost control: by considering the link between investment cost and asset life, and valuating intervention alternatives (Feliciano et al., 2014).

The smallest number of papers is about the BIM/GIS integration for infrastructure AM. Information management, during the asset's life-cycle (Hoeber and Alsem, 2016) and the interoperability between different technologies (Gilbert et al., 2021) are key topics. Besides these aspects, the integration of different types of data (geometric and non-geometric) has a great value for making predictions about networks, evaluating different scenarios, and improving current maintenance management systems (Love and Matthews, 2019).

The final stage of analysis is evaluating the articles according to the core AM function (Re Cecconi et al., 2020) and the main asset class. Asset classes in relation to the information management approach allow identifying where the three approaches are mainly used. Thanks to its capability to manage diverse data types, the GIS approach is applied to different types of infrastructure, both transportation and utility (Chatziioannou and Álvarez-Icaza, 2017). The BIM approach has been mainly used for the management of Bridges and Rail Transport networks (Love et al., 2017). Some articles have "no case study" because they have a theoretical approach and are referred especially to information management. In the case of BIM/GIS integration, the most addressed asset classes are roads and electrical energy networks (Aziz et al., 2017).

The last analysis is organised considering both the core AM functions (strategic, tactical and operational) and the authors' approach (BIM, GIS and BIM/GIS) to identify where the three approaches are mostly used. The analysis shows a greater interest in the GIS, especially for the strategic and tactical AM functions (see Fig. 2). GIS has been often used in risk, sustainability, resilience, and facility management, functions that are typically addressing the relationships among multiple infrastructural assets. A greater interest in BIM, especially in operational AM functions, can be found in facility, project and data management. The employment of methods based on BIM/GIS integration appears to be mainly explored in the Facility and Data Management functions, indicating a Tactical/Operational characterisation of this approach.

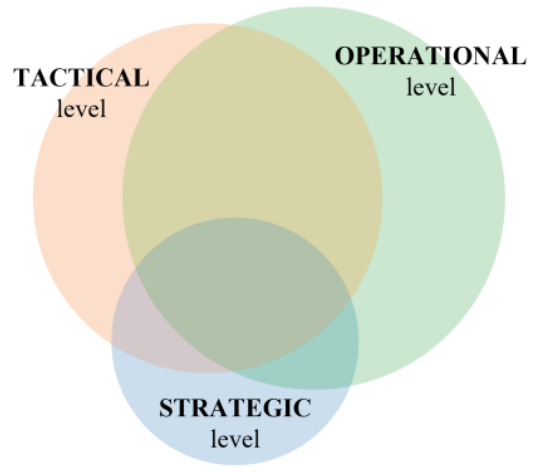

Figure 2. BIM/GIS Integration: Asset Management functions. Functions are described in Re Cecconi et al. (2020).

\subsection{Discussion}

The review allows identifying some knowledge gaps related to data management and interoperability. The main criticalities 
found are about the availability and accuracy of the as-built documentation, the problem of accessing the right/relevant information, and the time-consuming procedures for the extraction of information (Hoeber and Alsem, 2016). Data management improvement is essential to have the correct information: this is fundamental for enabling asset management to support activities and tasks of an asset. To access information from different scales, the integration of building data and geographic information is one of the interoperability's main challenges (Ellul et al., 2018). The conversion of BIM and GIS formats, that have different data standards, often produces a data loss (Zadeh et al., 2019). The integration of different data models is a delicate process and needs to be improved in order to automatize the matching between the corresponding objects of both standards. According to the AM functions results, most BIM/GIS articles have been addressed in Facility and Data management, indicating a tactical/operational characterisation of this approach. Considering the main features of BIM and GIS approaches, the integrated approach could be used for other functions, such as risk, resilience, and energy management, where multi-scale and cross-disciplinary problem are present.

\section{RESEARCH PROJECT}

The general objective of this work-in-progress research is to develop a BIM/GIS framework for the regional railways asset management to face the increasing demand for trains and help reach the decarbonisation target.

\subsection{Problem Statement}

As a result of the state-of-the-art analysis, BIM and GIS individually demonstrate to be effective tools for AM. The linear transport infrastructure is the asset class that was implemented and tested the most. Railways are an asset class on which to test the BIM/GIS integration might reveal a great potential since no references can be found to date. Lack of literature, EU's decarbonisation target, and social needs make the AM of regional railways an interesting research object. How important is railways development is even clearer considering, for instance, the new 2019-2023 Industrial Plan of Ferrovie dello Stato (FS), the major Italian manager of railway infrastructure (Ferrovie dello Stato, 2019). This plan focuses on quality and people's need by investing on regional transport. In addition, we should recall that 2021 was the European Year of Rail.

\subsection{Methodology}

The research framework follows a top-down and multi-scale approach based on a three-stage research methodology.

The first stage was the analysis of the general topic (BIM/GIS integration for AM) state of the art to define a more focused topic: regional/local railways.

The second stage was the digitization of the infrastructure, including two main steps: the railway analysis and the digital model creation. Starting from evaluating the existing documents and data, there will be the context reconstruction and evaluation in GIS environment to underline possible criticalities and restrictions. Then, the railway is modelled with different Levelof-Detail (LOD) in BIM environment. It is necessary to identify and categorize the digital tools to implement $3 \mathrm{D} / \mathrm{nD}$ design and support the model-based deliverables.

The third stage, the most difficult, involves BIM/GIS data integration to evaluate possible interventions and manage the chosen one. Thanks to the cross-domain information specific to each railway component, a more efficient AM system will be developed.

\subsection{Railway Description}

Railway infrastructures can be divided into different parts (Papathanasiou et al., 2018). Each part belongs to a specific object category that can be further divided into sub-categories. The granularity of the subdivision depends both on the required level of detail and on the available data. In the proposed methodology, objects are considered in the level of categories, not considering the different components that compose each item. Table 1 shows the list of railway items defined in the directive 2012/34/EU of the European Parliament and the Council of 2012 (European Parliament, 2012).

The list of items presented in Table 1 is the basis for defining the railway network. The entire network can be compared to two different types of elements: punctual and linear. The part of the network between two stations/stops is a line. Railways with more than one track have switches that define different routes (see Fig.3). Each route can be further divided into sections of homogeneous parts (bridge, tunnel and underpass).

\begin{tabular}{|c|c|}
\hline Item & Categories \\
\hline Ground area & Terrain \\
\hline \multirow{3}{*}{ Superstructure } & Track \\
\hline & Switch \\
\hline & Crossing \\
\hline \multirow{2}{*}{ Track bed } & Embankments \\
\hline & Cuttings \\
\hline \multirow{3}{*}{ Engineering structures } & Bridge \\
\hline & Tunnel \\
\hline & Protection structure \\
\hline \multicolumn{2}{|l|}{ Level crossing } \\
\hline \multirow{2}{*}{ Access ways } & Passenger platforms \\
\hline & Good platforms \\
\hline \multirow{3}{*}{$\begin{array}{l}\text { Safety, signalling and } \\
\text { telecommunications }\end{array}$} & Safety installations \\
\hline & Signalling installations \\
\hline & $\begin{array}{l}\text { Telecommunication } \\
\text { installations }\end{array}$ \\
\hline \multicolumn{2}{|l|}{ Lighting installations } \\
\hline \multirow{4}{*}{ Electric power supply } & Production plant \\
\hline & Substations \\
\hline & Supply cables \\
\hline & Catenaries \\
\hline Buildings & \\
\hline
\end{tabular}

Table 1. Items and categories of the railway infrastructure (European Parliament, 2012).

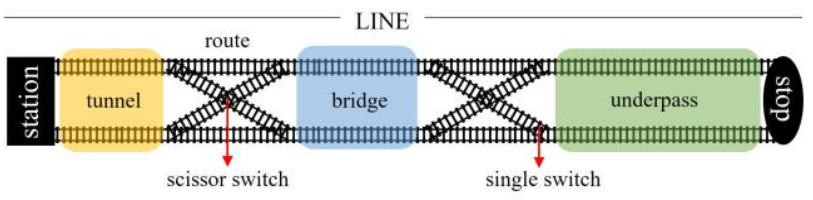

Figure 3. Railway network breakdown (adapted from Papathanasiou et al., 2018). 


\subsection{Digital Model}

The digital model is composed of two different elements: the GIS part and the BIM part. A BIM model is a digital representation of the physical (geometric) and functional (nongeometric) information of a project and can be used from the design to the maintenance phase to improve the efficiency of the projects, control their costs and reduce risks (Wang et al., 2019). GIS is a system to collect and manage spatial information and data about Earth's surface, and can be used in different applications (e.g. urban planning, disaster management, etc.). BIM pays more attention to micro-level data, while GIS focuses on macro-level data. The construction of the GIS model is made of different informative layers: areal (e.g., territory), linear (e.g., infrastructure) and punctual (e.g., stations). Different data sources were consulted in order to have a complete model. In parallel, a BIM model will be developed. Starting from the geometric characteristics of the railway, the elements (rails, ballast, sleepers, etc.) will be modelled with different LoDs. Geometric elements will be enriched by parameters and Key Performance Indicators (KPIs) about AM and usage.

\subsection{BIM/GIS integration}

Due to their different nature and modelling approaches in terms of semantics, geometry and LoD, the integration is a complex task and there is no optimal conversion between them. The flow of information always involves different data formats: Industry Foundation Classes (IFC - see buildingSMART, 2005) and City Geographic Markup Language (CityGML - see Open Geospatial Consortium, 2012) are the most relevant. IFC is a BIM open data standard, was developed by buildingSMART for data exchange (3D geometry). CityGML is an XML-based standard approved by Open Geospatial Consortium (OGC) used for urban information exchange (3D models of the city - see Zhu et al., 2018). The principal BIM-GIS integration methods are based on exporting data from BIM to GIS (GeoBIM), integrating GIS data into a BIM system or integrating both BIM and GIS data on a third-party platform (Song et al., 2017).

\section{CASE STUDY}

The railway company Ferrovie Appulo Lucane s.r.l. (FAL) administers a single-track, narrow gauged $(950 \mathrm{~mm})$, and nonelectrified railway track in the South of Italy. The track has a total length of about $190 \mathrm{~km}$, and it connects three major cities: Bari, the capital city of the Puglia region, Potenza, the capital city of the Basilicata region and Matera, an important touristic city (European Capital of Culture, 2019).

Table 2 defines the three main lines that compose the track.

\begin{tabular}{|l|c|c|c|}
\hline \multicolumn{1}{|c|}{ Line } & Opening date & Max slope & Max speed \\
\hline $\begin{array}{l}\text { Bari } \\
\text { Altamura } \\
\text { Matera }\end{array}$ & 1915 & $30 \%$ o & $100 \mathrm{~km} / \mathrm{h}$ \\
\hline $\begin{array}{l}\text { Altamura } \\
\text { Avigliano Lucania } \\
\text { Potenza }\end{array}$ & $1930-34$ & $50 \% 0$ & $70 \mathrm{~km} / \mathrm{h}$ \\
\hline $\begin{array}{l}\text { Avigliano Lucania } \\
\text { Avigliano Città }\end{array}$ & 1030 & $50 \% 0$ & $70 \mathrm{~km} / \mathrm{h}$ \\
\hline
\end{tabular}

Table 2. FAL main lines

The railway overcomes an altitude difference of about 800 meters: the highest point is Avigliano Città (876 m a.s.1.) and the lowest is Bari Centrale (12 $\mathrm{m}$ a.s.1.).

Figure 4 shows the railway track, the three principal stations and the position of all the stations and stops.

\subsection{Data collection}

In order to create a database as much comprehensive as possible, different data sources were consulted. The first set are GIS data taken from the National Geoportal (Geoportale Nazionale, n.d.) and, Puglia and Basilicata Regional Geoportals (Puglia.com, n.d.; RSDI Basilicata, n.d.). The second data set is derived from information published by FAL through the Service Chart and the Management System documents (Ferrovie Appulo Lucane, 2016), see Table 3. A third hybrid set of data (GIS and information) is provided by the National Institute of Statistic (ISTAT) (Istat, 2019).

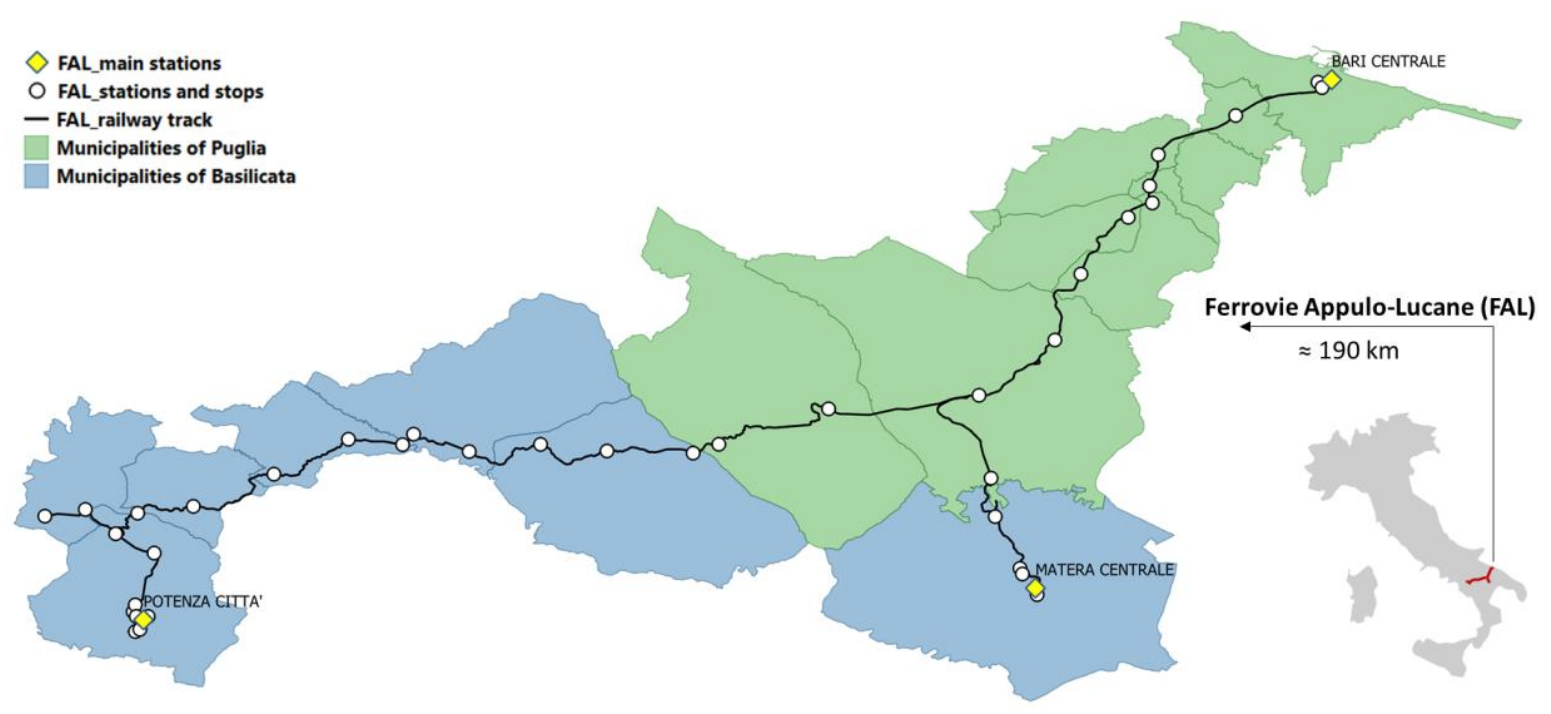

Figure 4. The railway-line network of Ferrovie Apulo-Lucane (FAL) with stations and stops. Data sources: rail lines and junctions from National and Regionals geodatabases, administrative boundaries from ISTAT. 


\begin{tabular}{|c|c|c|c|c|c|c|c|c|}
\hline & $\mathrm{ALu}$ & $-\mathrm{AC}$ & Alt - & $\mathrm{Lu}$ - PZ & BA - & It - MT & & OT \\
\hline & [n.] & {$[\mathrm{km}]$} & [n.] & {$[\mathrm{km}]$} & {$[\mathrm{n}]$.} & {$[\mathrm{km}]$} & [n.] & {$[\mathrm{km}]$} \\
\hline Lines & 2 & 7.72 & 21 & 103.53 & 16 & 75.74 & 39 & 186.99 \\
\hline Stations & 2 & 1 & 11 & 1 & 15 & 1 & 26 & 1 \\
\hline Stops & 1 & 1 & 11 & 1 & 2 & 1 & 14 & 1 \\
\hline Bridges & 5 & 0.49 & 67 & 1.99 & 56 & 1.22 & 128 & 3.7 \\
\hline Tunnels & 3 & 1.79 & 13 & 3.98 & 3 & 1.66 & 19 & 7.43 \\
\hline Underpasses & 0 & 0 & 17 & 0.25 & 29 & 0.52 & 46 & 0.77 \\
\hline Switches & 14 & 1 & 62 & 1 & 26 & 1 & 102 & 1 \\
\hline Level crossings & 1 & 1 & 22 & 1 & 17 & 1 & 40 & 1 \\
\hline Terminals & 7 & 1 & 35 & 1 & 20 & 1 & 62 & 1 \\
\hline
\end{tabular}

Table 3. FAL railway elements classification.

\subsection{GIS Model}

The GIS software QGIS (QGIS Association, 2021) was used to elaborate and analyse the data. The use of data from three Geoportals led to have different attribute tables. Before starting the analysis, it was necessary to standardize the attribute tables to have the same level of information. In 2015, AgID (Agenzia per l'Italia Digitale) published the second version of Geotopographic DataBases (GD), a list of technical specifications for the identification of spatial data (AgID, 2015). In addition to this list, custom attributes have been added:
- "ID": unique element identifier;

- "company": name of the operating companies. This attribute allows identifying rail tracks used by more than one company. In the case study presented, the Avigliano Lucania - Potenza Centrale line is shared between FAL and Rete Ferroviaria Italiana (RFI). Further work on hierarchy impacts will take it into account because its failure means outages for both the companies;

- "name": official denomination of stations/stops and lines; and

- "region": ISTAT classification code to identify stations/stops region.

Figure 5 describes the classification of rail elements and junctions and shows two examples of attribute tables (tunnel and station).

Standardized data allows to analyse and classify physical rail elements. Each line was divided by type of element: points (station, stop, level crossing, terminal, switch) and linear (at ground, bridge, tunnel, underpass).

\subsection{BIM Model}

GIS data are then connected into civil infrastructure software Autodesk Civil 3D ${ }^{\circledR}$ (Autodesk, 2021) to start with the model (see Fig. 6).

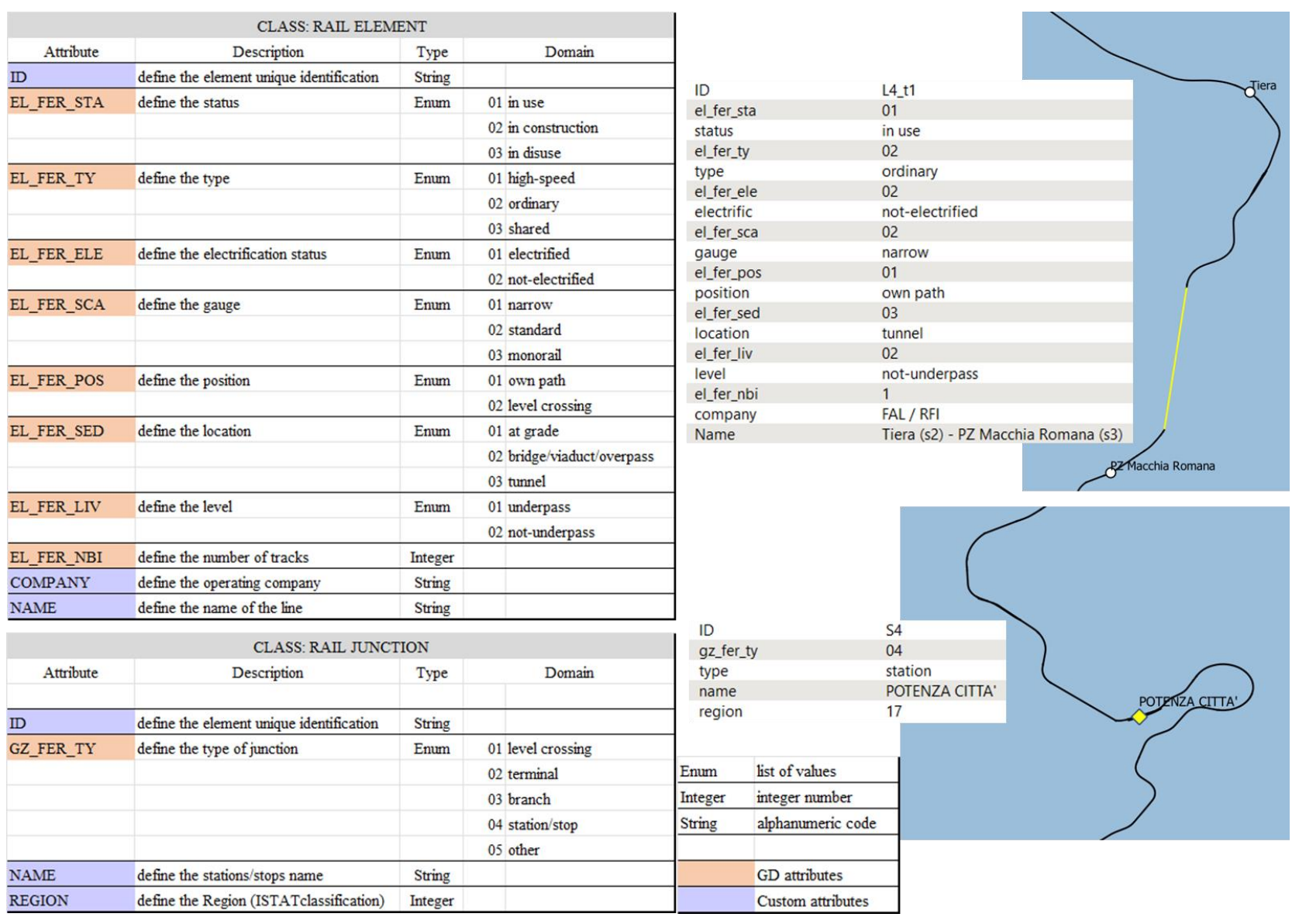

Figure 5. Rail lines and junctions classification; tunnel and station attribute tables. 

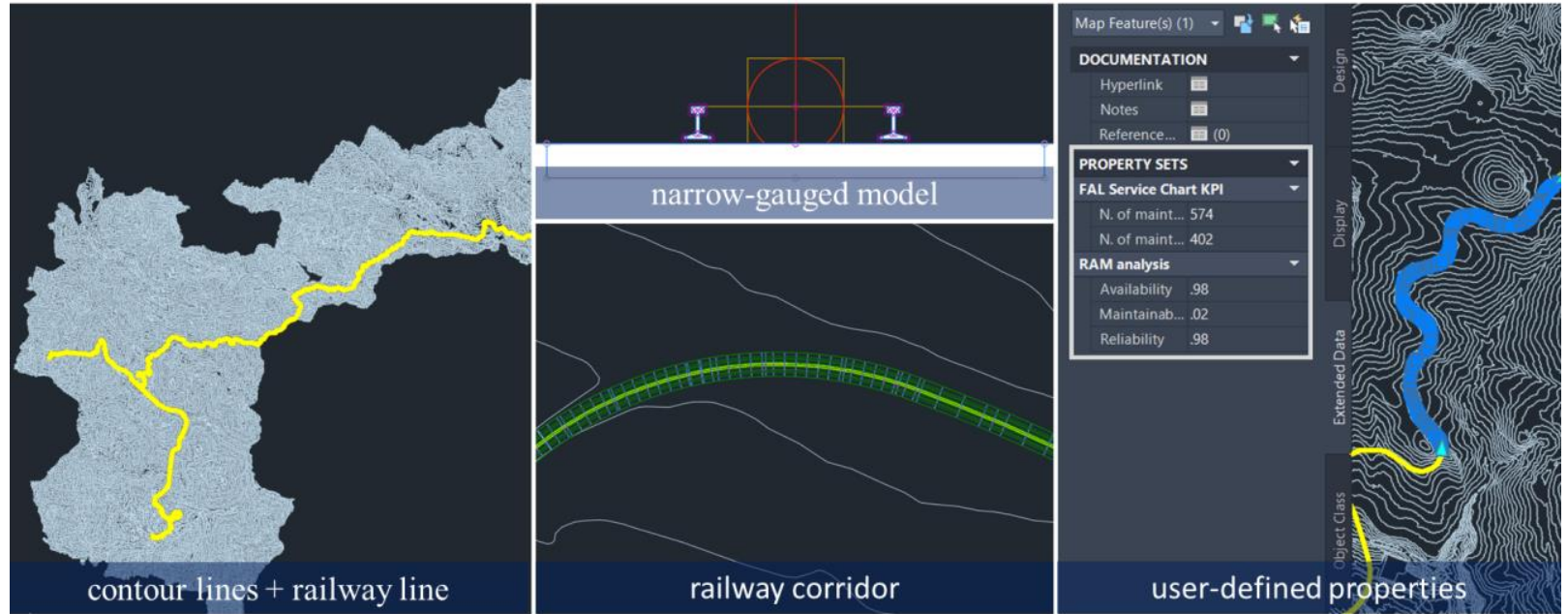

Figure 6. BIM model and properties.
Contour lines were used to generate the topographic surface and the railway line was considered as the model centreline.

A narrow-gauged section $(950 \mathrm{~mm})$ was set to build the rail corridor. Detail elements will be added.

Attached to geometry there is the information. In addition to the GIS properties showed above, the BIM model was enriched with two different property sets: one for the FAL Service chart key performance indicators (KPIs), that are number of scheduled and unscheduled maintenance works, and one for the Reliability, Availability and Maintainability (RAM) analysis, that defines indicators for the railway lifecycle (EN50126, 2017). The European standard defines: reliability as the ability of an item to perform as required, without failure, for a given time interval, under given conditions; availability as the ability of an item to be in a state to perform a required function under given conditions at a given instant of time or over a given time interval, assuming that the required external resources are provided; maintainability as the ability of an item to be retained in, or restored to, a state to perform as required, under given conditions of use and maintenance. Other property sets can be created as needed.

\section{CONCLUSIONS}

Considering the literature review, the decarbonisation policies, and the social aspects, the idea of this work in progress research is to integrated BIM and GIS technologies to handle the problem of renovation and management of regional railways. The aim is the construction of a system that can be used across different phases of the process: analysis of the existing condition, comparison with regulatory requirements, simulation of different intervention scenarios, and management of the implemented solution. The basis is the digitization of the railway components, the process of converting information into a digital format: each of them has geometric data (3D model), non-geometric data (type and functionality), and geographic data (position and context). A federated virtual model used as a single source of truth for a project.

A methodology was developed and partly tested on a case study. The use of BIM/GIS framework and the possibility to have model details and context data can support decisionmaking processes in the operation and maintenance field at a macro and micro level. Further work will consider the use of open file formats to improve the interoperability between different data sources and, to improve the quantity of the digital asset properties and information.

\section{ACKNOWLEDGEMENTS}

The authors would like to acknowledge: FAL, ISTAT, National Geoportal, Basilicata Geoportal, Puglia Geoportal, and Legambiente for the data; QGIS Association for the GIS opensource software they provide.

\section{REFERENCES}

Abdirad, H., Dossick, C.S., 2020. Rebaselining Asset Data for Existing Facilities and Infrastructure. J. Comput. Civ. Eng. 34. https://doi.org/10.1061/(ASCE)CP.1943-5487.0000868

AgID, 2015. Catalogo dei dati territoriali - Specifiche di Contenuto per i DB Geotopografici - Versione 2.0. (accessed 9.24.20)

Aria, M., Cuccurullo, C., 2017. bibliometrix: An R-tool for comprehensive science mapping analysis. J. Informetr. 11, 959975. https://doi.org/10.1016/J.JOI.2017.08.007

Autodesk, 2021. Civil 3D 2022. URL https://www.autodesk.it/products/civil-3d/overview?term=1YEAR\&tab=subscription $($ accessed 5.8.21)

Aziz, Z., Riaz, Z., Arslan, M., 2017. Leveraging BIM and Big Data to deliver well maintained highways. Facilities 35, 818832. https://doi.org/10.1108/F-02-2016-0021

BSI, 2017. EN 50126-1:2017.

buildingSMART, 2005. IFC standards . URL https://www.buildingsmart.org/ (accessed 5.8.21).

Chatziioannou, I., Álvarez-Icaza, L., 2017. Evaluation of the urban transportation infrastructure and its urban surroundings in the Iztapalapa County: A geotechnology approach about its management. Cogent Eng. 4. https://doi.org/10.1080/23311916.2017.1330854

Dell'Acqua, G., De Oliveira, S.G., Biancardo, S.A., 2018. Railway-BIM: Analytical review, data standard and overall 
perspective. Ing. Ferrov. 73, 901-923.

Ellul, C., Stoter, J., Harrie, L., Shariat, M., Behan, A., Pla, M., 2018. Investigating the state of play of GeoBIM across Europe. ISPRS - Int. Arch. Photogramm. Remote Sens. Spat. Inf. Sci. XLII-4/W10, 19-26. https://doi.org/10.5194/isprs-archivesXLII-4-W10-19-2018

European Parliament, 2012. Directive 2012/34/EU . URL https://eur-lex.europa.eu/legal-

content/EN/TXT/HTML/?uri=CELEX:02012L0034-

20190101\&from $=\mathrm{EN}$ (accessed 3.5.21).

EuropeanCommission, 2019. The European Green Deal . URL https://ec.europa.eu/info/sites/info/files/european-green-dealcommunication_en.pdf (accessed 9.24.20).

Feliciano, J., Almeida, R., Santos, A., Ganhão, A., Covas, D., Alegre, H., 2014. Energy efficiency in water distribution systems 'a path to an ideal network: AGS experience. Water Sci. Technol. Water Supply 14, 708-716. https://doi.org/10.2166/ws.2014.027

Ferrovie Appulo Lucane, 2016. Carta dei Servizi 2016-2019. URL https://ferrovieappulolucane.it/ (accessed 9.24.20)

Ferrovie dello Stato, 2019. 2019-2023 FS Industrial Plan. URL https://www.fsitaliane.it/content/dam/fsitaliane/en/Documents/i nvestor-relations/industrial-

plan/Industrial_Plan_FS_2019_2023.pdf (accessed 9.24.20).

Garramone, M., Moretti, N., Scaioni, M., Ellul, C., Re Cecconi, F., Dejaco, M.C., 2020. BIM and GIS Integration for Infrastructure Asset Management: A Bibliometric Analysis. ISPRS Ann. Photogramm. Remote Sens. Spat. Inf. Sci. VI-4/W120, 77-84. https://doi.org/10.5194/isprs-annals-VI-4-W1-2020$77-2020$

Geoportale Nazionale, n.d. Geoportale Nazionale . URL http://www.pcn.minambiente.it/mattm/

Gilbert, T., James, P., Smith, L., Barr, S., Morley, J., 2021. Topological integration of BIM and geospatial water utility networks across the building envelope. Comput. Environ. $\begin{array}{llll}\text { Urban Syst. } & 101570 .\end{array}$ https://doi.org/10.1016/j.compenvurbsys.2020.101570

Heaton, J., Parlikad, A.K., Schooling, J., 2019. Design and development of BIM models to support operations and maintenance. Comput. Ind. 111, 172-186. https://doi.org/10.1016/j.compind.2019.08.001

Hoeber, H., Alsem, D., 2016. Life-cycle information management using open-standard BIM. Eng. Constr. Archit. Manag. 23, 696-708. https://doi.org/10.1108/ECAM-01-20160023

ISO, 2014. ISO 55000:2014 Asset management Overview, principles and terminology.

Istat, 2019. Survey on Rail Trasportation. URL https://www.istat.it/en/ (accessed 9.24.20).

Legambiente, 2021. Pendolaria Report. URL https://www.legambiente.it/wp-

content/uploads/2021/02/Rapporto-Pendolaria-2021.pdf (accessed 9.24.20)
Love, P.E.D., Liu, J., Matthews, J., Sing, C.-P., Smith, J., 2015. Future proofing PPPs: Life-cycle performance measurement and Building Information Modelling. Autom. Constr. 56, 26-35. https://doi.org/10.1016/j.autcon.2015.04.008

Love, P.E.D., Matthews, J., 2019. The 'how' of benefits management for digital technology: From engineering to asset $\begin{array}{lll}\text { management. Autom. Constr. } & 107 .\end{array}$ https://doi.org/10.1016/j.autcon.2019.102930

Love, P.E.D., Zhou, J., Edwards, D.J., Irani, Z., Sing, C.-P., 2017. Off the rails: The cost performance of infrastructure rail projects. Transp. Res. Part A-Policy Pract. 99, 14-29. https://doi.org/10.1016/j.tra.2017.02.008

Nakamura, F., Ishiyama, N., Yamanaka, S., Higa, M., Akasaka, T., Kobayashi, Y., Ono, S., Fuke, N., Kitazawa, M., Morimoto, J., Shoji, Y., n.d. Adaptation to climate change and conservation of biodiversity using green infrastructure. River Res. Appl. https://doi.org/10.1002/rra.3576

Open Geospatial Consortium, 2012. OGC City Geography Markup Language (CityGML) Encoding Standard 2.0.0, Tech. rep. URL http://www.opengeospatial.org/standards/citygml (accessed 9.24.20)

Papathanasiou, N., Adey, B., Burkhalter, M., Martani, C., 2018. Risk Assessment Methodology. DESTination RAIL Deliverable D3.6.

Puglia.com, n.d. Puglia.con. URL http://www.sit.puglia.it/ (accessed 9.24.20)

QGIS Association, 2021. QGIS 3.16. URL https://www.qgis.org/it/site/index.html (accessed 9.24.20)

Re Cecconi, F., Dejaco, M.C., Moretti, N., Mannino, A., Blanco Cadena, J.D., 2020. Digital asset management, in: Research for Development. Springer, p. 243-253. https://doi.org/10.1007/978-3-030-33570-0_22

RSDI Basilicata, n.d. RSDI Basilicata. URL https://rsdi.regione.basilicata.it/ (accessed 9.24.20)

Scaioni, M., 2010. Evaluation of the Uncertainty of the Length of Energy Distribution Networks. Appl. Geomatics 2, 163175. https://doi.org/10.1007/s12518-010-0032-y

Song, Y., Wang, X., Tan, Y., Wu, P., Sutrisna, M., Cheng, J.C.P., Hampson, K., 2017. Trends and Opportunities of BIMGIS Integration in the Architecture, Engineering and Construction Industry: A Review from a Spatio-Temporal Statistical Perspective. ISPRS Int. J. Geo-Infom. 6. https://doi.org/10.3390/ijgi6120397

Torres-Machi, C., Osorio, A., Godoy, P., Chamorro, A., Mourgues, C., Videla, C., 2018. Sustainable Management Framework for Transportation Assets: Application to Urban Pavement Networks. KSCE J. Civ. Eng. 22, 4095-4106. https://doi.org/10.1007/s12205-018-1314-x

Tsakalidis, A., Gkoumas, K., Pekár, F., 2020. Digital transformation supporting transport decarbonisation: Technological developments in EU-funded research and innovation. Sustain. 12. https://doi.org/10.3390/su12093762 
United Nations, 2015. The Sustainable Development Goals. URL https://unric.org/it/agenda-2030/ (accessed 5.15.21).

Wang, H., Pan, Y., Luo, X., 2019. Integration of BIM and GIS in sustainable built environment: A review and bibliometric analysis. Autom. Constr. 103, 41-52. https://doi.org/10.1016/j.autcon.2019.03.005

Ward, B., Selby, A., Gee, S., Savic, D., 2017. Deterioration modelling of small-diameter water pipes under limited data availability. Urban Water J. 14, 743-749. https://doi.org/10.1080/1573062X.2016.1254252

Zadeh, P.A., Wei, L., Dee, A., Pottinger, R., Staub-French, S., 2019. BIM-CITYGML Data Integration for Modern Urban Challenges. J. Inf. Technol. Constr. 24, 318-340.

Zhu, J., Wright, G., Wang, J., Wang, X., 2018. A Critical Review of the Integration of Geographic Information System and Building Information Modelling at the Data Level. ISPRS Int. J. Geo-Inform. 7. https://doi.org/10.3390/ijgi7020066 